\title{
FEM Analysis of Effect of Rolling Parameters on Cold Rolling Process
}

\author{
K. Devarajan, K. Prakash Marimuthu and Dr. Ajith Ramesh
}

\begin{abstract}
A FEM simulation study was carried out to investigate the influence of the rolling parameters on the rolling process. Using commercial FEM software, ABAQUS, a number of cases were studied. In this paper, a twodimensional Elastic-plastic finite element model to simulate the cold rolling of thick strip with different roll angular velocity and roll diameter models is described. The angular velocity of the rigid rolls ranged from 30 to 480 revolutions per minute (r.p.m.) and the rigid roll diameter ranged from 100 to $300 \mathrm{~mm}$. The initial feeding speed of the plate and friction was kept constant, thus causing a slip between the plate and the roll surfaces. The main interest of this study is to see whether the speed of the rolls and the diameter of the rolls have any influence on the contact pressure and the residual stress in cold rolling process. The roll speed is an easily controlled operational parameter which may be used to enhance the process and the quality of the final products by changing the roller diameter and see the effect of stress and contact pressure on the thick plates strip is new one.
\end{abstract}

Keywords--- Contact Pressure, Von Mises Stress, Cold Rolling, Thick Plates

\section{INTRODUCTION}

$\mathrm{U}$ NTILL few years ago,the design of metal-forming tools, was mostly based on the knowledge gained through experience, and designing the optimum tool often required a protracted and expensive trial and error process [12]. To maintain the international competitiveness a roll must be able to produce products cost effectively.

With the development of science and technology, there are two main ways for steel manufactures to increase their competitiveness in steel manufacturing markets.One is to develop new products that are low cost; the other is to improve the quality of products with new mills and new technology introduced in the rolling practice [13]. The thick strip produced in a cold rolling mill has a wide applications in industry. However, a major handicap to producing an accurate

K. Devarajan, Department of Mechanical Engineering, Amrita School of Engineering, Amrita Vishwa Vidyapeetham, Coimbatore, Tamil Nadu, India. E-mail:devdharsu@yahoo.com

K. Prakash Marimuthu, PG Students, Department of Mechanical Engineering, Amrita School of Engineering, Amrita Vishwa Vidyapeetham, Coimbatore, Tamil Nadu, India. E-mail: prakashkmuthu@gmail.com

Dr. Ajith Ramesh, Department of Mechanical Engineering, Amrita School of Engineering, Amrita Vishwa Vidyapeetham, Coimbatore, Tamil Nadu, India.E-mail: ajith.pillai@gmail.com and reliable model for cold rolling of thick strip is the lack of a well-defined different roll diameter and roller speed are the conditions in the rolling process technology which introduces some problem. It is a challnge for researcher to overcome to this problem. Today, even in the early design phases, simulations of metal forming processes are performed using finite element methods. The main interest of this study is to see whether the roller speed and the diameter of the roller have any influence on the contact pressure, the Von Mises stresses in the thick strip materials. B.Wang, W.Hu, L.X.Kong, and P.Hodgson et al. [1] was studied residual stress, contact pressure and rolling force by changing the roll speed on the cold rolling of metal plates. J.C.Lin [2] was studied by changing the dimensions of the thin plates and roller diameter. Z.Y.Ziang and A.K.Tieu et al. [5] was simulated the cold rolling of thin plates with different friction model using 3D finite element analysis. Z.Y.Ziang and A.K.Tieu, X.M. Zhang and W.H.Sun et al. [6] was simulated the thin strip rolling taking into account the modeling of friction variation in the roll bite. All the authors mentioned above, are considered only two or three the rolling parameters in this cold rolling process and they did not include more number of simulations. But in this paper we considered almost all the parameters which we are using in the process and also we include, more number of simulations. In this paper we used response surface method to make more number of combinations.

\section{PROBLEM DEFINITION}

The primary objectives of the rolling process are to reduce the cross section of the incoming material while improving its properties and to obtain the desired section at the exit from the rolls. Figure 1, show that three dimensional rolling of thick plates. Based on the complexity of metal flow during the process and the geometry of the rolled product, the rolling of solid sections can be loosely divided into uniformed reduction in thickness with or without an increase in width, moderately non-uniform reduction in cross section and highly nonuniform reduction in cross section.

The steel plate of an original square cross section of 40 $\mathrm{mm}$ by $40 \mathrm{~mm}$ with a length of $100 \mathrm{~mm}$ is reduced to $30 \mathrm{~mm}$ in thickness by rolling through the one roll stand [1]. In this paper we described and analyzed the two dimensional rolling of thick plates. 


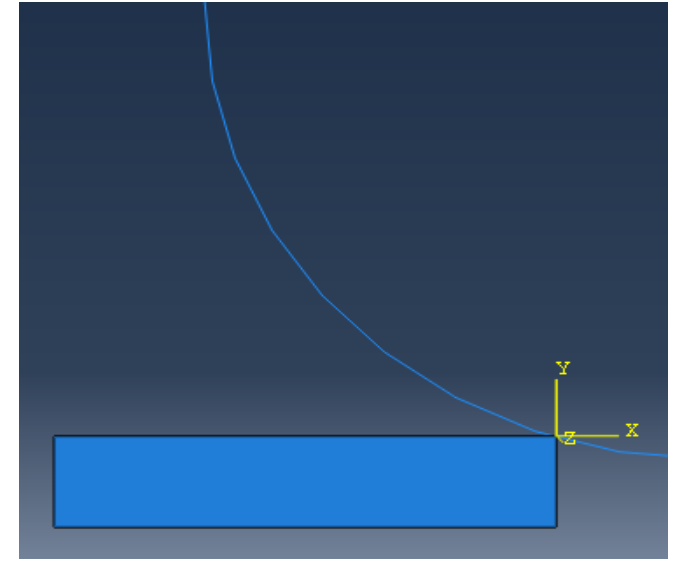

Figure 1: Two Dimensional Rolling of Thick Plates

\section{FINITE ELEMENT ANALYSIS}

The roller was modeled as rigid. Figure1. Show that assembly of the two dimensional model rolling of thick plates. The thick strip was modeled as elastic one and assumed thick plate was Isotropic elasticity, with Young's modulus of 150 $\mathrm{GPa}$ and Poisson's ratio of 0.33 and Strain hardening is described in Table 1. The methodology is used for this study Plane strain problem, Element $=\mathrm{CPE} 4 \mathrm{R}$ and Explicit Dynamic analysis [1].

Table 1: Strain Hardening Rate

\begin{tabular}{|c|c|}
\hline Yield Stress (MPa) & $\begin{array}{c}\text { Plastic } \\
\text { Strain }\end{array}$ \\
\hline 168.72 & 0 \\
\hline 219.33 & 0.1 \\
\hline 272.02 & 0.2 \\
\hline 308.53 & 0.3 \\
\hline 337.37 & 0.4 \\
\hline 361.58 & 0.5 \\
\hline 382.65 & 0.6 \\
\hline 401.42 & 0.7 \\
\hline 418.42 & 0.8 \\
\hline 434.01 & 0.9 \\
\hline 448.45 & 1 \\
\hline
\end{tabular}

No rate dependence and temperature dependence are taken into account. The plate was given an initial velocity of 1.037 $\mathrm{m} / \mathrm{s}$ before entering the roll gap. Figure 2 shows schematically the meshed model.

Boundary condition of this cold rolling is the initial step the strip is given an initial velocity so that the strip touches the roll. In the step I the strip is constrained in the ' $y$ ' direction, initial velocity is given to thin plates in ' $x$ ' direction and the roller rotates given angular velocity with respect its reference point. Figure 3 show that boundary condition of rolling of thick plates.

This velocity is equal to the horizontal component of the surface velocity of the roll at the entry point, when the roller rotates at different r.p.m, roller have different diameter and the initial speed of the plate was kept constant in all cases while the rolls were given different spin speeds as shown in Table 1.

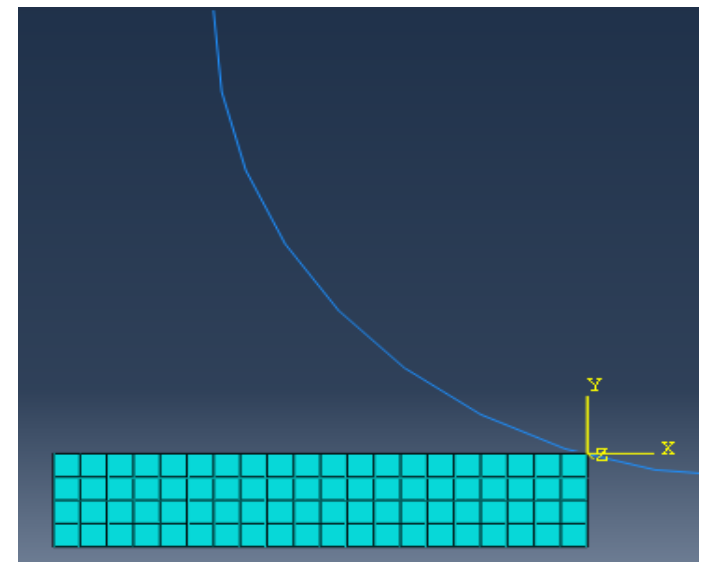

Figure 2: Model of the Plate to Be Rolled

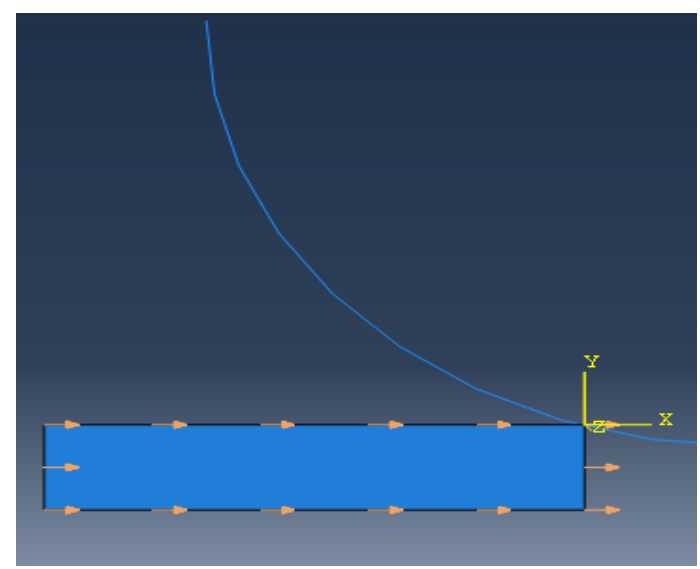

Figure 3: Boundary Conditions of Rolling of Thick Plates

Table 2: Values of Parameters Used in the Simulation

\begin{tabular}{|c|c|c|c|c|}
\hline $\begin{array}{c}\text { Case } \\
\text { No }\end{array}$ & $\begin{array}{c}\text { Rolls } \\
\mathrm{rpm}\end{array}$ & $\begin{array}{c}\text { Roll initial } \\
\text { velocity in } \\
\mathrm{m} / \mathrm{s}\end{array}$ & $\begin{array}{c}\text { Roll } \\
\text { Diameter } \\
\text { in } \mathrm{mm}\end{array}$ & Friction \\
\hline 1 & 30 & 1.037 & 100 & 0.3 \\
\hline 2 & 60 & 1.037 & 150 & 0.3 \\
\hline 3 & 120 & 1.037 & 200 & 0.3 \\
\hline 4 & 240 & 1.037 & 250 & 0.3 \\
\hline 5 & 320 & 1.037 & 275 & 0.3 \\
\hline 6 & 480 & 1.037 & 300 & 0.3 \\
\hline
\end{tabular}

\section{NUMERICAL SIMULATIONS}

The main interest of this Study of contact pressure and Von misses stress for different roll diameters and angular velocity of the roll in cold rolling process. The roll speed is an easily controlled operational parameter which may be used to enhance the process and the quality of final products. Figure 4. Shows typical simulation results of the rolling process which clearly illustrates deformed profile of the plate. Figure 5 gives the distribution of the contact pressure normal to the top surface (top view).

As it shown in Figure 6, the contact pressure increases rapidly to a peak level shortly after the entrance point then drops and maintains its value until another peak just before the exits point. The contact pressure is more clearly revealed in Figure 6 and 7 which shows for constant roll diameter = 
$250 \mathrm{~mm}$, the contact pressure along the contact arc between the roll and the plate. It gives a typical twin peak distribution with the second peak (close to the exits point) occurring at about the neutral point in the six case of diameter [3].

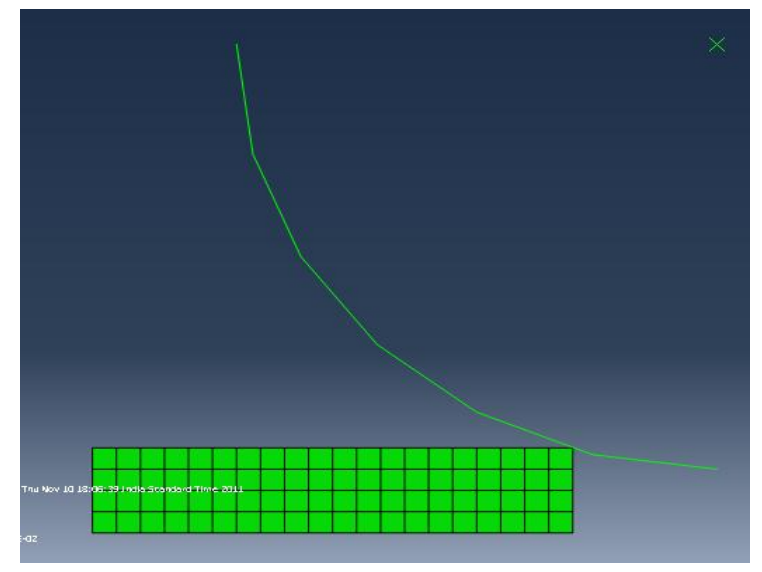

Figure 4: Simulated Results during the Process of Rolling

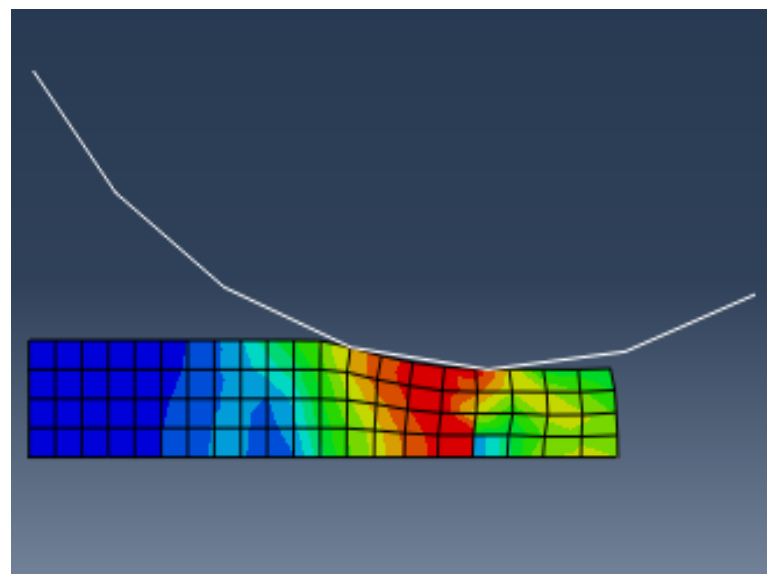

Figure 5: Distribution of Contact Pressure over the Thick Plate

The first peak appears to be not sharper than the second one which is similar to George E.Dieter [3] mentioned in mechanical metallurgy. The pressure also tends to be oscillatory along the contact arc when the roll speed is higher. This is probably due to disappearance of the neutral point for the higher roll speed cases in the study.

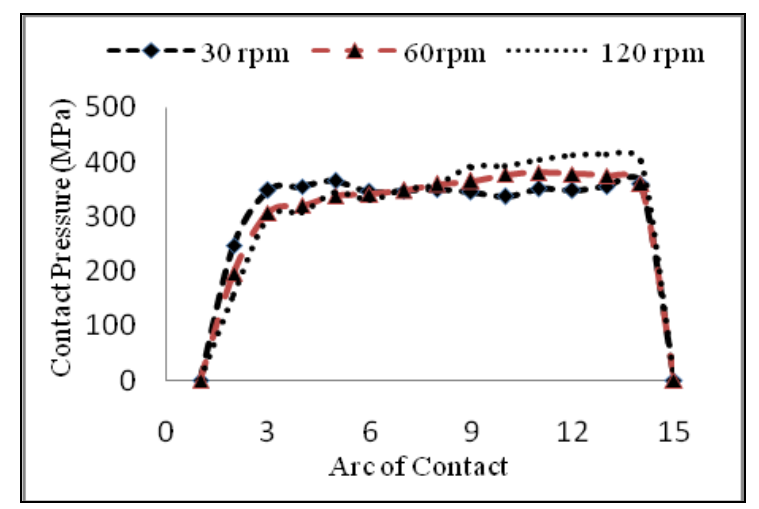

Figure 6: Graph between Arc of Contact for Different Roller Speed and Contact Pressure for case 30, 60,120 rpm for Constant Roller Diameter $=250 \mathrm{~mm}$ and Friction $=0.3$
For the case of the highest roll speed, the pressure curve becomes not only oscillatory, but also flattened, indicating a more averaging distribution of pressure along the contact arc [1]. Figure 8. Illustrates for constant roller speed $=240 \mathrm{rpm}$, the trend of the maximum level of the residual in the processed plate with respect to the diameter of the rolls. It is clearly shows that a Von Mises stress decreasing trends when increasing the roller diameter. The Figure7.Suggest that if a higher roller diameter is used during the operation, the proceed plate will have a lower magnitude of residual stress.

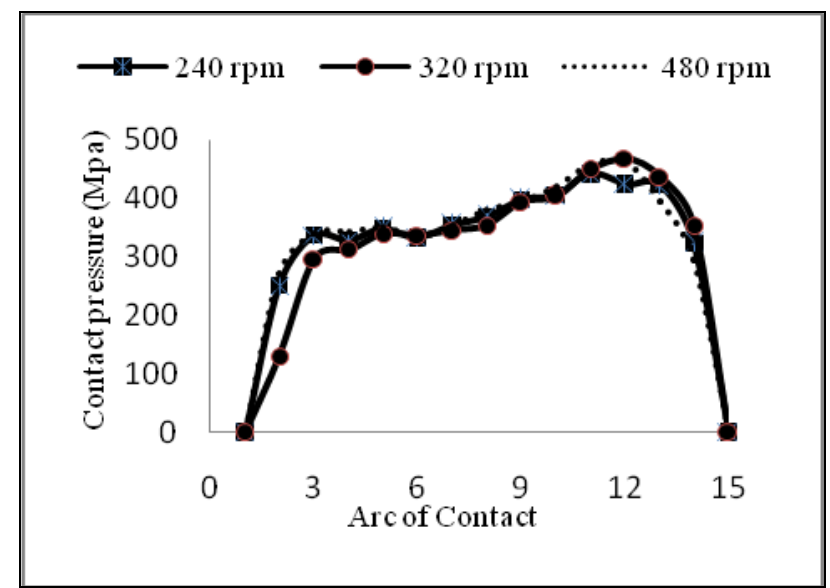

Figure 7: Graph between Arc of Contact for Different Roller speed and Contact Pressure for Case 240,320,480 rpm for

Constant Roller Diameter $=250 \mathrm{~mm}$ and Friction $=0.3$

\section{EFFECT OF ROLLING PARAMETERS}

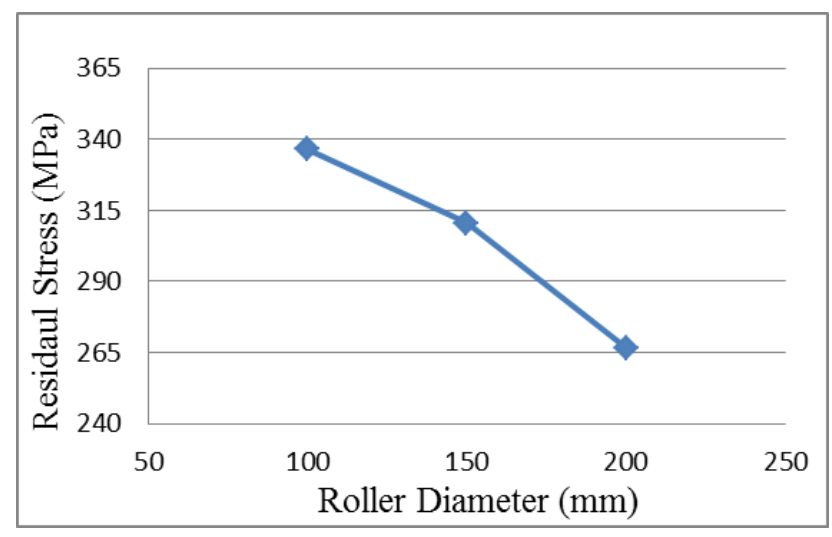

Figure 8: Residual Stresses vs. Roller Diameter. Initial Thickness of 4mm, Friction Coefficient of 0.2, Roller Speed of $40 \mathrm{rpm}$ and \% of Reduction of $17.5 \%$

Form the above Figure we understood that, residual stress decrease with increasing roller diameter. After some increment of roller diameter, the residual stress will be constant with increasing roller diameter.

The above Figure 8; illustrates the trend of the maximum value of the residual stress in the processed sheet with respect to the spin speed of the rolls. It clearly shows that a higher roll speed will produce a more uniform residual stress distribution in the sheet metal. The figure suggests that if a higher rolling speed is used during the operation, the processed sheet metal 
will have a lower magnitude of residual stress.

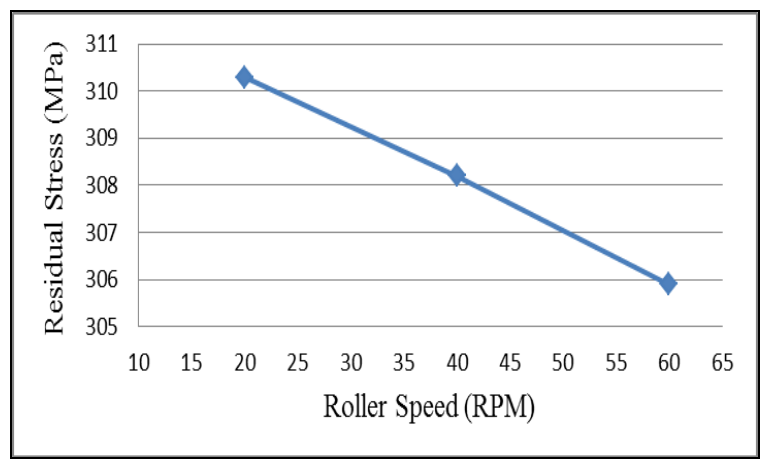

Figure 9: Residual Stress vs. Roller Speed. Initial Thickness of $4 \mathrm{~mm}$, Roller Diameter of $150 \mathrm{~mm}$, Friction Coefficient of 0.2 and $\%$ of Reduction of $17.5 \%$

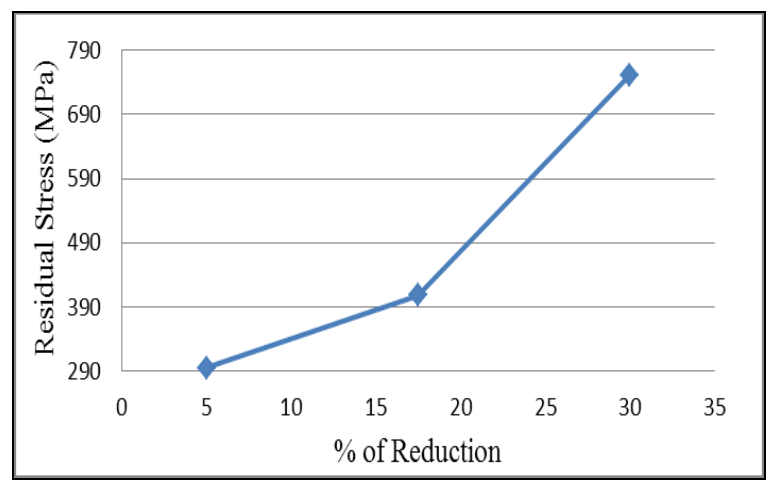

Figure 10: Residual Stress vs. Percentage of Reduction. Initial Thickness of 4mm, Roller Diameter of 150mm, Roller Speed of $40 \mathrm{rpm}$ and Friction Coefficient of 0.2

Form the above Figure 10; we understood that, residual stress increases with increasing percentage of reduction. After some increments of percentage reduction, the residual stress will reach steady state value with increasing roller diameter.

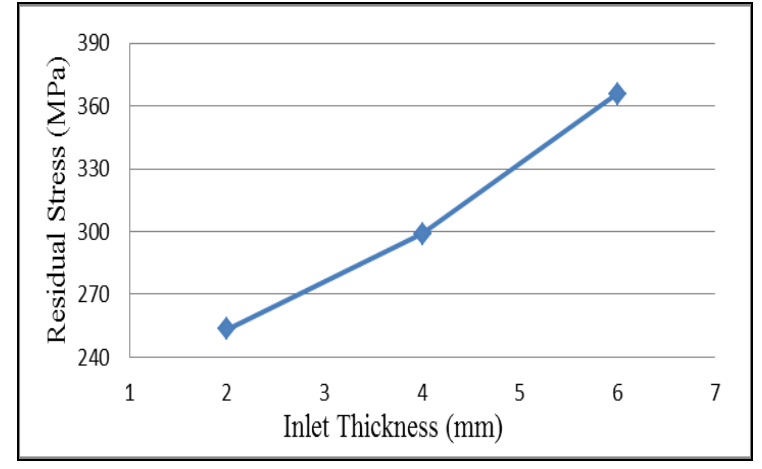

Figure 11: Residual Stress vs. Initial Thickness. Roller Diameter of $150 \mathrm{~mm}$, Roller Speed of $40 \mathrm{rpm}$, Friction Coefficient of 0.2 and \% of Reduction of $17.5 \%$

Form the above Figure 11; we understood that, residual stress increases with increasing inlet thickness. Keep on increasing the size of inlet thickness, the residual stress will increase.

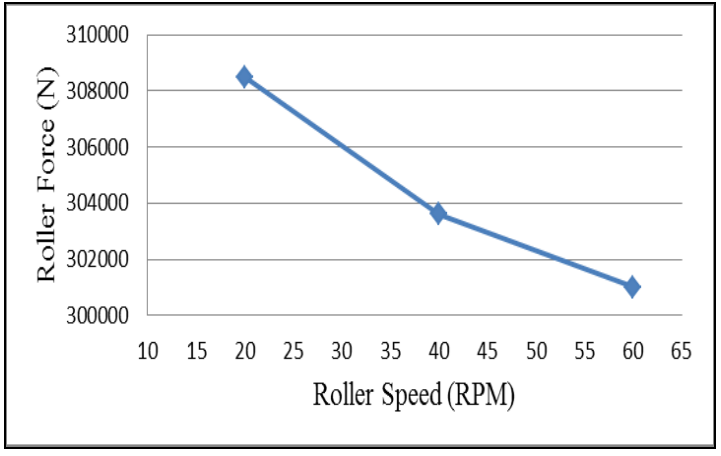

Figure 12: Rolling Force vs. roller Speed. Initial Thickness of $4 \mathrm{~mm}$, Roller Diameter of $150 \mathrm{~mm}$, Friction Coefficient of 0.2 and $\%$ of Reduction of $17.5 \%$

Form the above Figure 12; we understood that, rolling force decreases with increasing roller speed. Because, if the roller speeds increases mean the roller making contact with material not proper and force acting on the material will reduced.

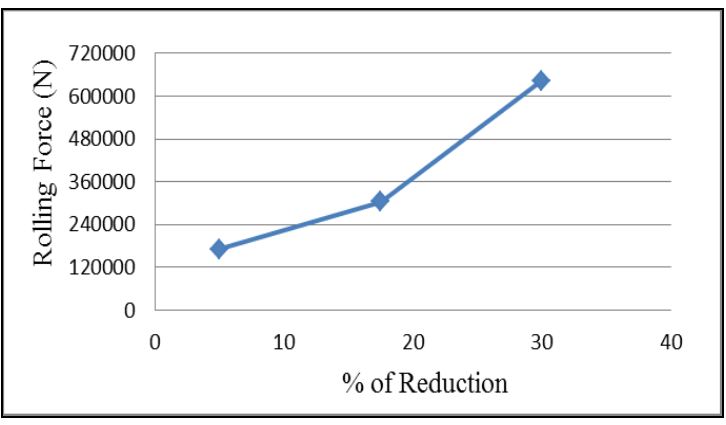

Figure 13: Rolling Force vs. \% of Reduction. Initial Thickness of 4mm, Roller Diameter of $150 \mathrm{~mm}$, Roller Speed of $40 \mathrm{rpm}$ and Friction Coefficient of 0.2

Form the above Figure 13; we understood that, rolling force increases with increasing percentage of reduction each cycle. If percentage of reduction increases in each roller stand, the roller making contact with material is perfect and force acting on the material.

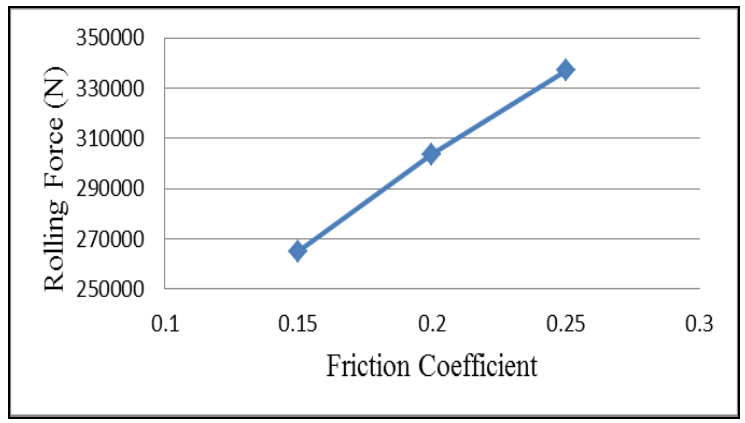

Figure 14: Rolling Force vs. friction Coefficient. Initial Thickness of $4 \mathrm{~mm}$, Roller Diameter of $150 \mathrm{~mm}$, Roller Speed of $40 \mathrm{rpm}$ and \% of Reduction of $17.5 \%$ 


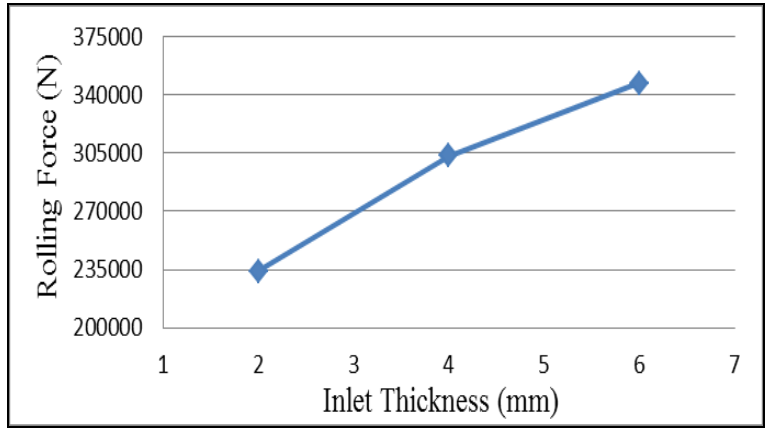

Figure 15: Rolling Force vs. Inlet Thickness. Friction Coefficient of 0.2, Roller Diameter of 150mm, Roller Speed of $40 \mathrm{rpm}$ and $\%$ of Reduction of $17.5 \%$

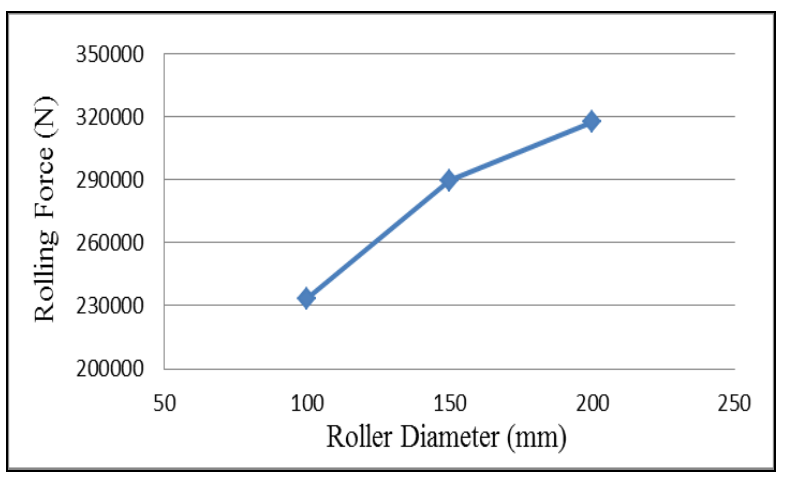

Figure 16: Rolling Force vs. roller Diameter. Friction Coefficient of 0.2, Initial thickness of 4mm, Roller Speed of $40 \mathrm{rpm}$ and \% of Reduction of $17.5 \%$

The above Figure 16; shows that when the roll diameter increases, the Rolling Force increases. With a larger work roll diameter, both the contact length and the contact area of the roll bite increases, and therefore raise higher rolling force. Therefore, in order to reduce the load on the rolling mill and save the energy in the rolling process, it is necessary to reduce the diameter of the work roll if practicable.

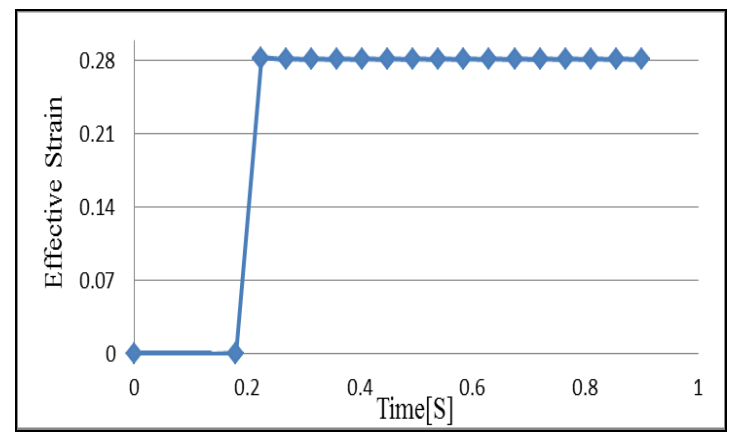

Figure 17: Effective Strain Histories at the Center Point

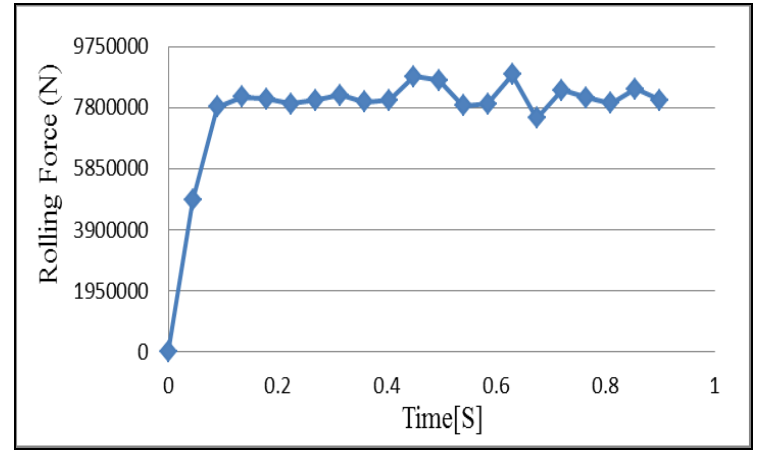

Figure 18: Rolling Force Histories during Rolling Process

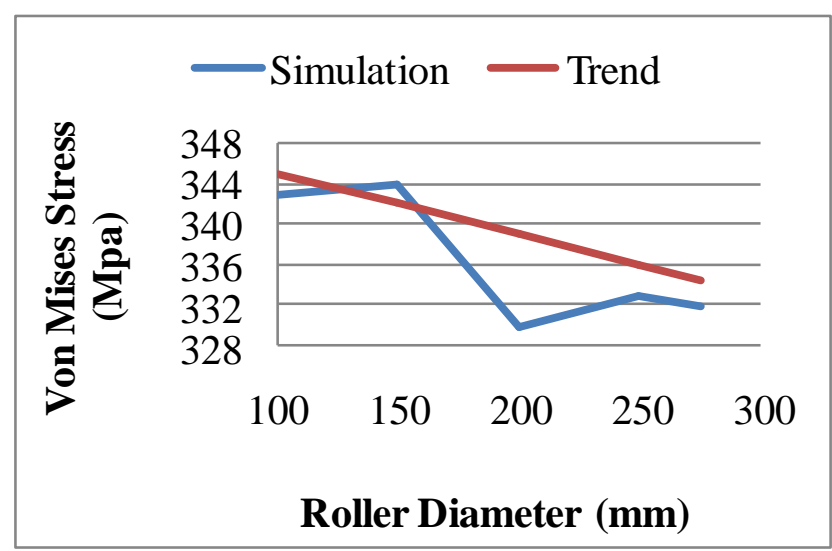

Figure 19: Graph between Different Roller Diameter and VonMises Stress for Constant Roller Speed=240 rpm and Constant Friction $=0.3$

\section{SUMMARY AND DECISIONS}

A study based on purely numerical solutions was carried out to investigate the influence of the roller speed and roller diameter on the cold rolling process.

1. From the analysis of contact pressure, the FEM results match with the theoretical results, that is the contact pressure gradually rises from the entry, reaches maximum at the neutral point and then decreases as the strip exits from the roller.

2. From the study of the Von Mises stress for different diameters of the roll we can understand that there is a decreasing trend for achieving the same thickness.

3. Roller speed increases, the rolling force keep on decreases, because the roller making contact on the strip with less time if the roller force is very high.

4. Future enhancement is to find the effect of rolling parameters in hot rolling process.

\section{REFERENCES}

[1] B.Wang, W. Hu, L.X. Kong and P. Hodgson, "The Influence of Roll Speed on the Rolling of Metal Plates", Journal of metals and materials, Vol. 4, No. 4, Pp. 919-919,1998.

[2] J.C.Lin "Prediction of Rolling Force and Deformation in ThreeDimensional Cold Rolling by Using the Finite-Element Method and a Neural Network", International journal of manufacturing technology, Springer-Verlog ,Vol. 20, Pp. 799-806, 2002.

[3] George E. Dieter, Mechanical Metallurgy, $2^{\text {nd }}$ edition, McGraw-Hill Book \& Co, London, 
[4] LIU Xiang-hua ,SHI Xu ,LI Shan-qing, XU Jian-yong, "FEM Analysis of Rolling Pressure Along Strip Width in Cold Rolling Process", International journal of iron and steel research, Science direct, Vol. 14, No. 5, Pp.22-26, 2010.

[5] Z.Y. Jiang, A.K. Tieu, "A 3-D finite element method analysis of cold rolling of thin strip with friction variation", Tribology International, Science direct, Vol. 37, No.37, Pp.185-191, 2004.

[6] Z.Y. Jiang, A.K. Tieu, X.M. Zhang, C. Lu a, W.H. Sun "Finite element simulation of cold rolling of thin strip", Journal of Materials Processing Technology, science direct, Vol. 140, No. 140,Pp. 542547, 2003.

[7] Morris J.W, Hardy S.J, Lees A.W, Thomas J.T, "Formation of residual stress owing to tension levelling of cold rolled strips", ISSN 2001; 28:0-1,2001.

[8] Datta A.K, Das G, De P.K, Ramachandrarao P, Mukhopadhyaya M, "Finite element modeling of rolling process and optimization of process parameter", Journal of material science and engineering, Elsevier 426: Pp. 11-20, 2006.

[9] Akbari Mousavi S.A.A, Ebrahimi S.M, Madoliat R, "Three Dimensional numerical analyses of asymmetric rolling", Journal of Materials Processing Technology, Science direct 2007;187: Pp. 725729,2005 .

[10] Galantucci, L.M., and Tricario, L. "Thermo-Mechanical simulation of a rolling process with an FEM approach", Journal of Materials Processing Technology, Elsevier, Vol.92, No.93, Pp. 494-501, 1999.

[11] Jiang, Z.Y., Xiong, S.W., Tieu, A.K., and Jane Wang, Q. "Modelling of the effect of friction on cold strip rolling", Journal of Materials Processing Technology, Science direct, Vol. 201, Pp.85-90, 2008.

[12] K. Roll, "Advanced Simulation Techniques - Exceeding Reality", materials science and technology, 2007.

[13] D.J. Jim, Y.C. Kim and B.M. Kim, "Optimization of the Irregular Shape Rolling Process with an Artificial Neural Network", Journal of Materials Processing Technology, 2001. 